\title{
LOCALIZAÇÃO GEODÉSICA DA LINHA DE PREAMAR MÉDIA COM RELAÇÃO AO ANO DE 1831, NA PRAIA DO FUTURO/ FORTALEZA-CE, BRASIL
}

\author{
GEODESIC LOCATION OF THE LINE OF MEDIUM HIGH TIDE WITH \\ RELATIONSHIP TO THE YEAR OF 1831, IN THE BEACH OF FUTURO/ \\ FORTALEZA-CE, BRAZIL
}

\section{LOCALISATION GÉODÉSIQUE DE LA LIGNE MOYENNE DE MARÉ HAUTE PAR RAPPORT À L'ANNÉE 1831, À PRAIA DO FUTURO / FORTALEZA-CE, BRÉSIL}

Paulo Roberto Lopes Thiers - Universidade Federal do Ceará - Fortaleza - Ceará - Brasil

pthiers@ufc.br

\begin{abstract}
Resumo
0 presente trabalho tem por fim apresentar resultados, descrição de metodologia para a representação cartográfica, em escala cadastral, da localização geodésica da Linha de Preamar Média (LPM) e Linha de Terrenos de Marinha (LTM), com referência ao ano de 1831, em área da Praia do Futuro, localizada na cidade de Fortaleza, Estado do Ceará. Para a realização do estudo, foram utilizados métodos que envolvem conceitos de geodésia, cartografia e técnicas de sensoriamento remoto. Ao longo de toda a linha da costa brasileira há situações que descrevem a ocupação da faixa de terrenos de marinha: terrenos pertencentes à União. Os resultados da determinação da LPM possibilitam o posicionamento da LTM, que é a distância horizontal de $33 \mathrm{~m}$, contados a partir da LPM. 0 estudo representa, graficamente, a ocupação da faixa de terrenos de marinha da Praia do Futuro, por edificações/barracas. Este trabalho, parte da perícia encomendada pela Justiça Federal no Estado do Ceará, conclui que, efetivamente, apenas parte de estruturas das barracas da Praia do Futuro ocupa terrenos da União.
\end{abstract}

Palavras-chave: terrenos de marinha, sensoriamento remoto, sistema de posicionamento global (GPS).

\section{Abstract}

The present work aims to present results, methodology description for the cartographic representation, in cadastral scale, of the geodesic location of the Line of Medium High tide (LMH) and Line of Lands of Navy (LLN), with reference to the year of 1831, in area of the Beach of the Future, located in the city of Fortaleza, state of Ceará. For the accomplishment of the study they were used methods that involve geodesy concepts, cartography and techniques of remote sensing. He/she/you comes across, along the whole line of Brazilian coast, with situations that describe the occupation of the strip of navy lands: lands belonging to the Union. The results of the determination of LMH make possible the positioning of LLN, that is the horizontal distance of $33 \mathrm{~m}$, counted starting from LMH. This work, leaves of the expertise ordered by the Federal Justice in the State of Ceará, it concludes that, indeed, just part of structures of the huts of the Beach of the Future, occupies lands of the Union.

Key words: navy lands, remote sensing, global positioning system (GPS).

\section{Resumen}

Cet article descrit la méthodologie employée dans la représentation cartographique de la carte cadastrale, indiquant l'emplacement de la ligne géodésique de marée haute moyenne (LPM) et de la ligne de Terres de La Marine (LTM), ayant comme référence l'année 1831, dans le domaine de la Plage du Futuro, situé à Fortaleza, Ceará/Brésil. Pour mener l'étude on a utilisé des méthodes bases sur les concepts de la géodésie, de la 
cartographie et des techniques de télédétection. Tout au long de la ligne cotière du Brésil on trouve des scénarios caracterisant l'occupation de terrains dont le proprietaire c'est l'Union. Les résultats de la recherche permettent la détermination du positionnement LPM et de la LTM, la distance horizontale de $33 \mathrm{~m}$, à partir de la LPM. Ainsi l'étude permet représente graphiquement la logique d'occupation de la bande cotière par des paillotes. Mots-clés: ligne de terres de la marine, télédétection, global positioning system (GPS).

Introdução

O Instituto Brasileiro de Geografia e Estatística (IBGE) implantou a Rede Maregráfica Permanente para a Geodésia (RMPG), composta de cinco estações digitais: Imbituba-SC, Macaé-RJ, Salvador-BA, FortalezaCE e Belém-PA, com a pretensão de determinar elementos que permitam a correlação do datum de Imbituba-SC com outros referenciais maregráficos. O marégrafo de Imbituba-SC é o datum geodésico vertical no Brasil, referência para a Rede Altimétrica de Alta Precisão (RAAP), utilizada para estudos científicos, mapeamento, construção de estradas, obras de saneamento, irrigação, telecomunicações, usinas hidrelétricas e outras aplicações, em que a questão da origem das altitudes assume grande importância (IBGE, 2006).

O cálculo da cota básica da LPM, com retroação a 1831, foi efetuado com dados observados, no Porto do Mucuripe, pela Diretoria de Hidrografia e Navegação, relativos ao período de 2005 a 2009. Para efetiva determinação da linha geodésica que define a LPM, consoante à Lei n. 9.760 de 1946, com vistas a atender aos objetivos a que se propõe este trabalho, foi realizada a correlação dos dados do nível do mar local com o marégrafo de Imbituba-SC, utilizando-se de conceitos e técnicas de geodésia e cartografia.

Os estudos para a determinação da faixa de terrenos de marinha, neste trabalho, foram conduzidos com o objetivo de fornecer elementos que permitissem esclarecer se edificações (barracas) construídas na Praia do Futuro estariam em Terrenos de Marinha, compreendidos como pertencentes à União.

\section{Elaboração da Base de Dados Espaciais}

A produção da base de dados da Praia do Futuro envolveu procedimentos que dependeram de fontes de informações com características espaciais das entidades gráficas envolvidas: barracas, LPM, LTM e topô- 
nimos. Para a referência planimétrica, foi utilizado o datum geodésico horizontal SAD69/96 (South American Datum 69, realização 1996). Para a representação altimétrica, foi utilizado o datum vertical Marégrafo de Imbituba-SC.

A técnica de sensoriamento remoto é destaque na produção da informação geoespacial, em que os sistemas sensores fornecem imagens de alta resolução espacial para a obtenção rápida de informações detalhadas e precisas. Já o Sistema Global de Navegação por Satélites (GNSS), para posicionamento terrestre, pode alcançar precisões geodésicas de $3 \mathrm{~mm}+$ 0,5ppm, com receptores de dupla frequências (L1/L2). Sobre o assunto, Monico (2008) afirma:

Posicionar um objeto nada mais é do que lhe atribuir coordenadas. Embora atualmente esta seja uma tarefa que pode ser realizada com relativa simplicidade, utilizando-se, por exemplo, satélites artificiais apropriados para esse fim, determinar a posição foi um dos primeiros problemas científicos que o ser humano procurou solucionar.

Os elementos de marés utilizados neste trabalho foram observados e analisados pela Diretoria de Hidrografia e Navegação da Marinha (DHN), utilizando-se de método harmônico. O período de observação de dados corresponde ao período de 16/2/1995 a 26/3/1995, consoante ficha maregráfica F-41- Padrão - Porto de Mucuripe - 30340 - versão 1/2009 (Figura 1), Carta n. 701 - Porto de Mucuripe. À ficha maregráfica juntamse o Diagrama e o Esquema (Figura 2) representativos da situação real do Porto de Mucuripe: 


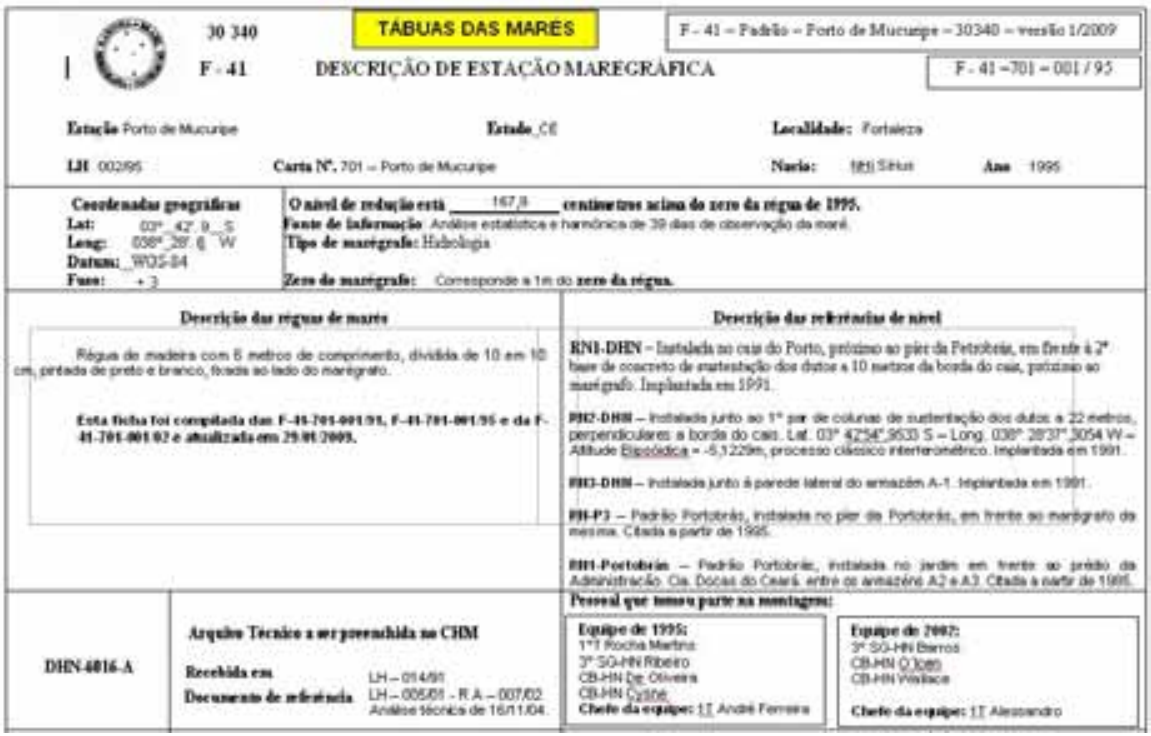

Figura 1 - Ficha Maregráfica

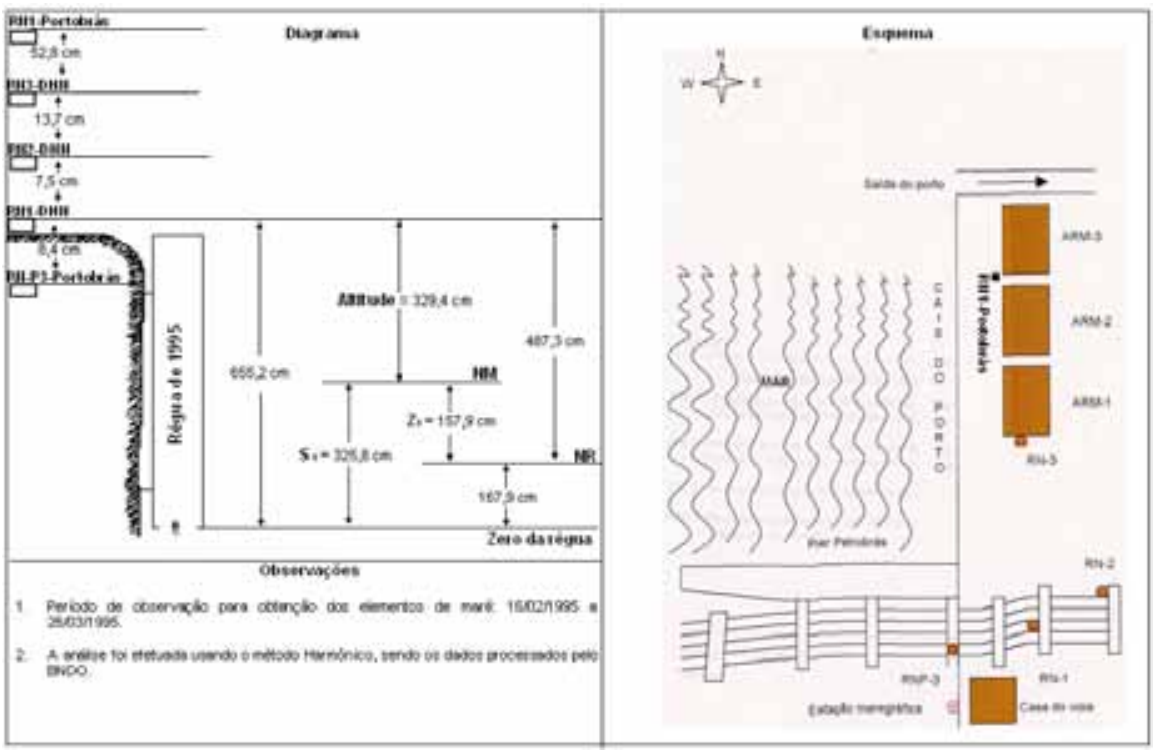

Figura 2 - Diagrama e Esquema do Porto do Mucuripe 
Artigo

Correlação do NMM Local com o Marégrafo de Imbituba-SC

Para o cálculo da altitude da Preamar Média, foi utilizada a Referência de Nível RN1- Portobrás, com altitude de 4,034m, instalada no jardim em frente ao prédio da Administração Cia. Docas do Ceará, entre os armazéns A2 e A3.

Para efetuar a correlação do Nível Médio Local ao datum vertical do Sistema Geodésico Brasileiro, Marégrafo de Imbituba-SC, foi utilizada a Referência de Nível RN 9320T, pertencente à Rede Altimétrica de Alta Precisão (RAAP), gerenciada pelo IBGE.

Enfatize-se que as referências de nível RN1-Portobrás e RN9320T são coincidentes, ou seja, o mesmo monumento apresenta valores altimétricos referenciados a data distintos: datum do Porto de Mucuripe (DHN) e Marégrafo de Imbituba-SC (IBGE), respectivamente.

\section{Transporte de coordenadas do sistema geodésico brasileiro}

Com o objetivo de georreferenciar os produtos cartográficos gerados para o presente trabalho, foi efetuado o transporte de coordenadas planialtimétricas (E, N, H) para uma estação-base, a partir de estações de referências da Rede Brasileira de Monitoramento Contínuo (RBMC): CRAT, localizada na cidade de Crato e CEEU, instalada na cidade de Eusébio. De acordo com dados do IBGE,

a utilização da tecnologia GPS (Global Positioning System) provocou uma verdadeira revolução, nesta última década, nas atividades de navegação e posicionamento. Os trabalhos geodésicos e topográficos passaram a ser realizados de forma mais rápida, precisa e econômica. Tais vantagens vêm melhorando cada vez mais, à medida que os equipamentos, os métodos de observação e as técnicas de processamento evoluem. É nesse contexto que se insere a RBMC.

Nas aplicações geodésicas e topográficas do GPS, está implícita a utilização do método relativo, isto é, ao menos uma estação de coordenadas conhecidas é também ocupada simultaneamente à ocupação dos pontos desejados. Antes da RBMC, o usuário interessado em obter, com GPS, as coordenadas geodésicas de um ponto qualquer em território nacional era obrigado a trabalhar com dois receptores, ocupando o ponto de seu interesse e um marco do Sistema Geodésico Brasileiro (SGB) próximo.

As estações da RBMC desempenham justamente o papel do ponto de coordenadas conhecidas, eliminando a necessidade de que 
o usuário imobilize um receptor em um ponto que, muitas vezes, oferece grandes dificuldades de acesso. Além disso, os receptores que equipam as estações da RBMC são de alto desempenho, proporcionando observações de grande qualidade e confiabilidade. (IBGE, 2010)

Os dados observados continuamente pelos receptores da RBMC foram processados em triangulação com o receptor geodésico instalado na Praia do Futuro, dupla frequência (L1/L2), marca Topcon e modelo Hiper, posicionado sobre marco de concreto (estação-base). A estação-base, instalada em canteiro da barraca Vira Verão, foi utilizada como referência para o processamento de todos os pontos do levantamento.

O processamento das observações GPS foi efetuado com referência ao datum geocêntrico SIRGAS2000,4 (Sistema de Referência Geocêntrico para as Américas), e datum geodésico vertical Marégrafo de ImbitubaSC, com base no Sistema de Projeção Universal Transverso de Mercator (UTM). Para controle de qualidade, foi realizado o ajustamento dos dados observados e fechamento de circuito da figura, em triangulação: CRAT, CEEU e estação-base.

As coordenadas horizontais (E, N) da estação-base são:

$$
\mathrm{E}=560551,962 \mathrm{~m} \quad \text { e } \quad \mathrm{N}=9587076,624 \mathrm{~m}
$$

A altitude ortométrica $(\mathrm{H})$ da estação de referência dos trabalhos (estação-base) foi determinada por rastreamento da RN 4336A, pertencente à RAAP, e localizada no Porto de Mucuripe, próxima à estação maregráfica do IBGE.

Os receptores de sistemas de posicionamento observam valores referentes às altitudes geométricas ou alturas elipsoidais (h), portanto, valores referenciados ao elipsoide utilizado. A altitude ortométrica refere-se ao geoide e, para a sua determinação, rastreando com receptores de dupla frequência (L1/L2), foi aplicada a fórmula $h=H+N$. A variável $N$ é determinada no mapa geoidal Mapgeo2010 (IBGE/USP).

Considerando que o Ponto (1) é a RN 4336A, e que o Ponto (2) é a estação-base, o cálculo para a altitude ortométrica, pela aplicação da fórmula abaixo descrita, resultou $\mathrm{H}=5,966 \mathrm{~m}$. 


$$
\begin{gathered}
\Delta \mathrm{h}=\Delta \mathrm{H}+\Delta \mathrm{N} \\
\mathrm{h}_{2}-\mathrm{h}_{1}=\left(\mathrm{H}_{2}-\mathrm{H}_{1}\right)+\left(\mathrm{N}_{2}+\mathrm{N}_{1}\right) \\
\mathrm{H}_{2}=\mathrm{H}_{1}+\left(\mathrm{h}_{2}-\mathrm{h}_{1}\right)-\left(\mathrm{N}_{2}+\mathrm{N}_{1}\right)
\end{gathered}
$$

Ponto (1) - RN 4336A

Ponto (2) - Estação-base

$\mathrm{N}$ - ondulações geoidais obtidas por Mapgeo2010 (IBGE/USP);

$\mathrm{H}$ - altitude ortométrica (referência de nível obtida da RAAP)

$\mathrm{H}$ - altura elipsoidal ou altitude geométrica (determinada por observações do sistema GPS/GNSS).

A qualidade da determinação altimétrica da estação-base foi verificada por comparação com resultados de transporte das estações de referência geodésica do IBGE: CRAT e CEEU, por determinação através de Posicionamento por Ponto Preciso (utilizando efemérides precisas) e nivelamento geométrico de precisão.

As informações altimétricas de toda a faixa de praia foram obtidas através de levantamento de perfis e pontos notáveis do terreno para a geração do Modelo Digital do Terreno e curvas de níveis, para representação das formas de relevo da área de trabalho.

Para o levantamento dos perfis, foram utilizados receptores geodésicos de dupla frequência (L1/L2) do sistema GPS, utilizando o método cinemático contínuo.

\section{Análise de Medições Maregráficas}

Foram analisadas as medições maregráficas observadas no Porto do Mucuripe, no município de Fortaleza, e monitoradas pela DHN no período de 1\%1/2005 e 30/6/2009 (Tabela 1), tendo em vista a determinação da cota básica da LPM.

A DHN forneceu tabela de dados do período acima citado, com observações horárias obtidas em régua de 6m, com o Nível de Redução localizado a 167,9 cm acima do Zero desta. Para o cálculo da altura da Preamar Média, foram utilizados dados referentes às marés máximas (sizígia), limitando o período de observação para 1\%1/2005 a 30/6/2009 (Tabela 1), atendendo orientação da Instrução Normativa n. 2, de 12 de março de 2001. 
O processamento dos dados observados compreendeu o cálculo da média aritmética, que corresponde ao valor mais provável da série histórica dos valores de marés de sizígia, e a determinação do desvio padrão para fornecer o grau de incerteza dessas observações. A Preamar Média para o período foi de 3,093m +/- 0,091m.

Tabela 1

Preamares Máximas (marés de sizígia): 1\%1/2005 a 30/6/2009

\begin{tabular}{|c|c|c|c|c|c|}
\hline Data & Hora & Altura(m) & Data & Hora & Altura(m) \\
\hline $11 / 1 / 2005$ & 7h 26 & 3,2 & $16 / 4 / 2007$ & $15 \mathrm{~h} 56$ & 3,1 \\
\hline $8 / 2 / 2005$ & 16h 28 & 3,2 & $17 / 5 / 2007$ & $4 \mathrm{~h} 45$ & 3,0 \\
\hline $10 / 3 / 2005$ & $6 \mathrm{~h} 56$ & 3,2 & $15 / 6 / 2007$ & $4 \mathrm{~h} 30$ & 3,0 \\
\hline $8 / 4 / 2005$ & 4h 23 & 3,0 & $15 / 7 / 2007$ & $5 \mathrm{~h}$ & 3,0 \\
\hline $7 / 5 / 2005$ & 3h 54 & 2,9 & 29/8/2007 & 4h 53 & 3,1 \\
\hline $23 / 6 / 2005$ & $5 \mathrm{~h} 13$ & 3,1 & $26 / 9 / 2007$ & 16h 19 & 3,1 \\
\hline $22 / 7 / 2005$ & $5 \mathrm{~h} 02$ & 3,2 & $25 / 10 / 2007$ & $15 \mathrm{~h} 53$ & 3,1 \\
\hline $20 / 8 / 2005$ & $4 \mathrm{~h} 49$ & 3,2 & $24 / 11 / 2007$ & $16 \mathrm{~h} 17$ & 3,1 \\
\hline $18 / 9 / 2005$ & 4h 30 & 3,2 & $24 / 12 / 2007$ & $16 \mathrm{~h} 54$ & 3,1 \\
\hline $17 / 10 / 2005$ & 4h 11 & 3,1 & $22 / 1 / 2008$ & $16 \mathrm{~h} 43$ & 3,1 \\
\hline $14 / 11 / 2005$ & 3h 11 & 2,9 & $8 / 2 / 2008$ & $17 \mathrm{~h} 28$ & 3,0 \\
\hline $31 / 12 / 2005$ & 16h 51 & 3,0 & $8 / 3 / 2008$ & $17 \mathrm{~h} 09$ & 3,1 \\
\hline $29 / 1 / 2006$ & 16h 38 & 3,2 & $6 / 4 / 2008$ & 4h 34 & 3,1 \\
\hline $27 / 2 / 2006$ & 16h 21 & 3,2 & $6 / 5 / 2008$ & 4h 56 & 3,1 \\
\hline $1 / 3 / 2006$ & 17h 53 & 3,2 & $4 / 6 / 2008$ & $4 \mathrm{~h} 43$ & 3,1 \\
\hline $26 / 4 / 2006$ & 3h 28 & 3,0 & $3 / 7 / 2008$ & 4h 32 & 3,1 \\
\hline $26 / 5 / 2006$ & $3 \mathrm{~h} 47$ & 2,9 & $1 / 8 / 2008$ & 4h 19 & 3,1 \\
\hline $13 / 6 / 2006$ & $5 h 24$ & 2,9 & $1 / 9 / 2008$ & $5 h 21$ & 3,0 \\
\hline $13 / 7 / 2006$ & $5 \mathrm{~h} 58$ & 3,1 & $15 / 10 / 2008$ & $4 \mathrm{~h} 24$ & 3,0 \\
\hline $11 / 8 / 2006$ & $5 \mathrm{~h} 45$ & 3,2 & $14 / 11 / 2008$ & $17 \mathrm{~h} 13$ & 3,1 \\
\hline $8 / 9 / 2006$ & $4 h 41$ & 3,2 & $12 / 12 / 2008$ & $16 \mathrm{~h} 15$ & 3,1 \\
\hline $7 / 10 / 2006$ & 4h 21 & 3,2 & $11 / 1 / 2009$ & $16 \mathrm{~h} 54$ & 3,2 \\
\hline $4 / 11 / 2006$ & $15 \mathrm{~h} 43$ & 3,1 & $9 / 2 / 2009$ & 16h 41 & 3,2 \\
\hline $4 / 12 / 2006$ & 16h 06 & 3,0 & $10 / 3 / 2009$ & $16 \mathrm{~h} 23$ & 3,1 \\
\hline $20 / 1 / 2007$ & $17 \mathrm{~h} 30$ & 3,1 & $26 / 4 / 2009$ & $5 \mathrm{~h} 08$ & 3,0 \\
\hline $18 / 2 / 2007$ & $17 \mathrm{~h} 15$ & 3,2 & $25 / 5 / 2009$ & 4h 54 & 3,0 \\
\hline $19 / 3 / 2007$ & $17 \mathrm{~h} 00$ & 3,2 & $23 / 6 / 2009$ & 4h 41 & 3,1 \\
\hline \multicolumn{5}{|l|}{ Preamar Média } & $3,093 \mathrm{~m}$ \\
\hline \multicolumn{5}{|l|}{ Incerteza } & $0,091 \mathrm{~m}$ \\
\hline
\end{tabular}


Cálculo da cota básica da Preamar Média na Praia do Futuro

A determinação da Cota Básica (Figura 3) da Preamar Média no Porto de Mucuripe foi efetuada sobre a RN1-Portobrás, pertencente ao datum local. A correlação entre a RN1-Portobrás com o Marégrafo de ImbitubaSC já havia sido realizada através de nivelamento de alta precisão pelo IBGE. Portanto, a sua incorporação à Rede Altimétrica de Alta Precisão (RAAP) recebeu a denominação de RN 9320T, facilitando, sobremaneira, o desenvolvimento dos trabalhos. Dessa forma, o cálculo da Cota Básica da LPM, com relação aos dados de 2005/2009, pode ser feito assim:

$$
\begin{gathered}
\text { Cota Básica }=\text { PM }- \text { Zo }+(\text { RN9320T }- \text { RN1/Portobrás }) \\
\text { Cota Básica }=309,3 \mathrm{~cm}-157,9 \mathrm{~cm}+(475,6 \mathrm{~cm}-403,4 \mathrm{~cm})
\end{gathered}
$$

Cota Básica $=2,24 \mathrm{~m}$

PM - Preamar Média no período de 01/01/2005 a 30/06/2009;

Zo - Constante harmônica do modelo de previsão utilizado para o cálculo da cota do NMM local em relação ao Nível de Redução (NR): equivale a $157.9 \mathrm{~cm}$,

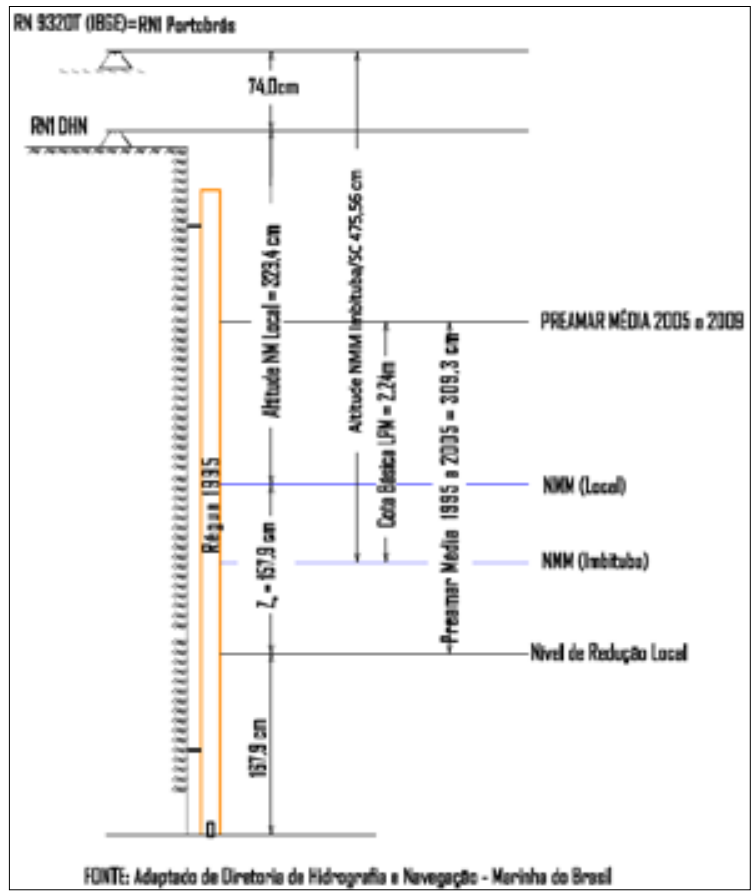

Figura 3 - Diagrama para Determinação da Cota Básica 
RN1-Portobrás - Referência de nível determinada com relação ao Nível Médio do Mar Local (MNML/Porto de Mucuripe (Fortaleza-CE)) e corresponde a 4,034m;

RN9320T - Referência de Nível determinada com relação ao datum vertical do Sistema Geodésico Brasileiro (Marégrafo de Imbituba-SC) e corresponde a 4,7556m.

Cálculo da Ipm com retrovisão ao ano de 1831

Na Praia do Futuro, para o cálculo da cota básica da LPM relativa a 2009, verifica-se que a constante harmônica Zo $=157,9 \mathrm{~cm}$ (Figura 4) é a cota do NMM local com relação ao Nível de Redução da régua no Porto de Mucuripe/Fortaleza-CE, constante da ficha maregráfica do Porto de Mucuripe, fornecida pela DHN.

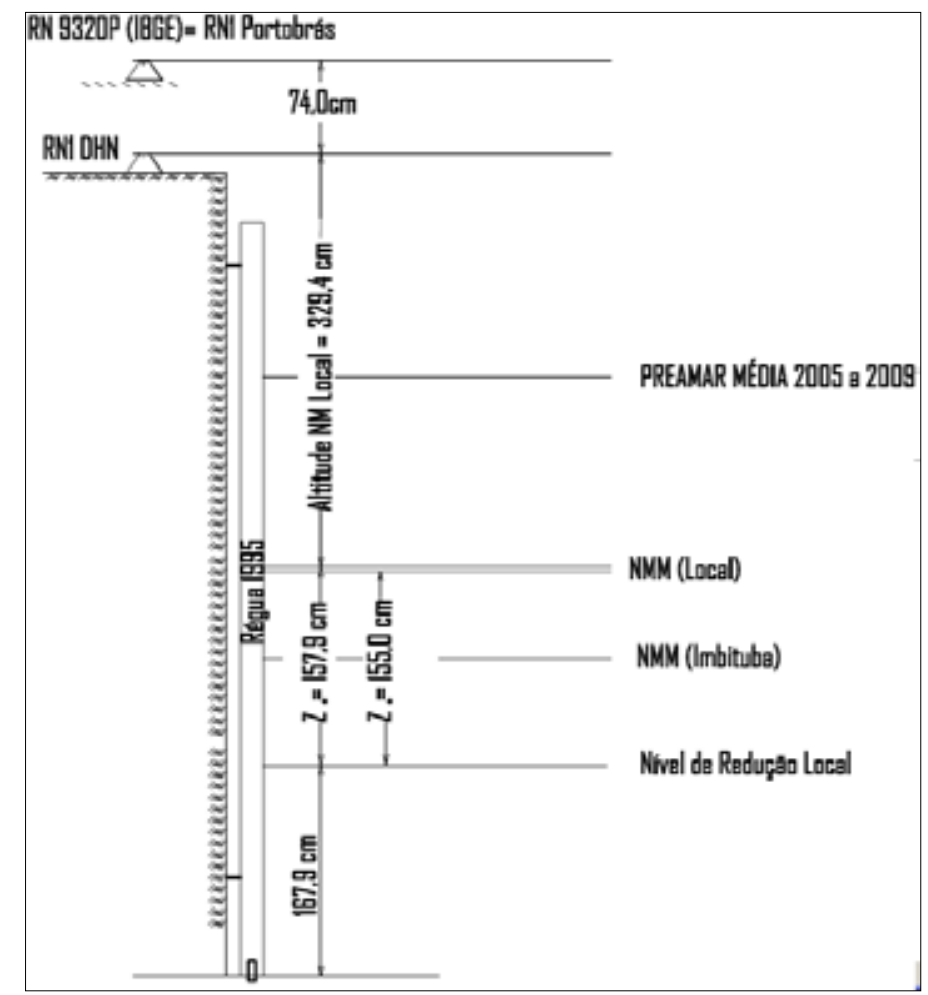

Figura 4 - Adaptado de Diretoria de Hidrografia e Navegação - Marinha do Brasil 
Por outro lado, nos trabalhos realizados em outros trechos do litoral cearense, pelo Serviço de Patrimônio da União observa-se que o valor da constante harmônica contido na ficha maregráfica para o ano de 1993 é $\mathrm{Zo}=155,0 \mathrm{~cm}$. Portanto, com base nesses valores, constata-se que houve variação do nível médio do mar local, no período de 1993 a 2004, equivalente a $2,9 \mathrm{~cm}$.

Admitindo-se o ano de 1993 como referência, a variação de tempo para o ano de 2009 é de 16 anos, e a taxa de variação do nível médio local em Porto de Mucuripe é de 1,8mm/ano.

Com base nessa taxa de variação, extrapolando valores, conclui-se que o NMM local subiu $32 \mathrm{~cm}$ desde o ano de 1831. O resultado obtido reforça a afirmação de Blitzkow et al. (2001) de que "[...] o nível médio do mar de longo termo está aumentando na costa brasileira.”

Portanto, a retrovisão a 1831 será efetuada através da diferença da variação do nível médio dos mares, equivalente a $32 \mathrm{~cm}$, em relação ao valor da Cota Básica de 2,24m, calculada para o Porto do Mucuripe em 2009:

Cota Básica $=2,24 \mathrm{~m}-0,32 \mathrm{~m}=1,92 \mathrm{~m}$

\section{Localização da Ipm/1831 na Praia do Futuro/Fortaleza-CE}

A Cota Básica da Preamar Média do Porto de Mucuripe, rigorosamente determinada, é a mesma para a área da Praia do Futuro, vista que o NMM local é, certamente, o mesmo para as duas áreas perante a curta distância que as separam.

A Linha de Preamar Média (LPM) e a Linha de Terreno de Marinha (LTM) - esta localizada a 33m contados da LPM em direção ao continente, como determina o Decreto-lei n. 9.760, de 5 de setembro de 1946 - foram lançadas em carta na escala de 1:2.000. A área de abrangência formada pelas LPM e LTM engloba os Terrenos de Marinha (Figura 5). Foram elaboradas 12 folhas articuladas e na escala de 1:2.000. 


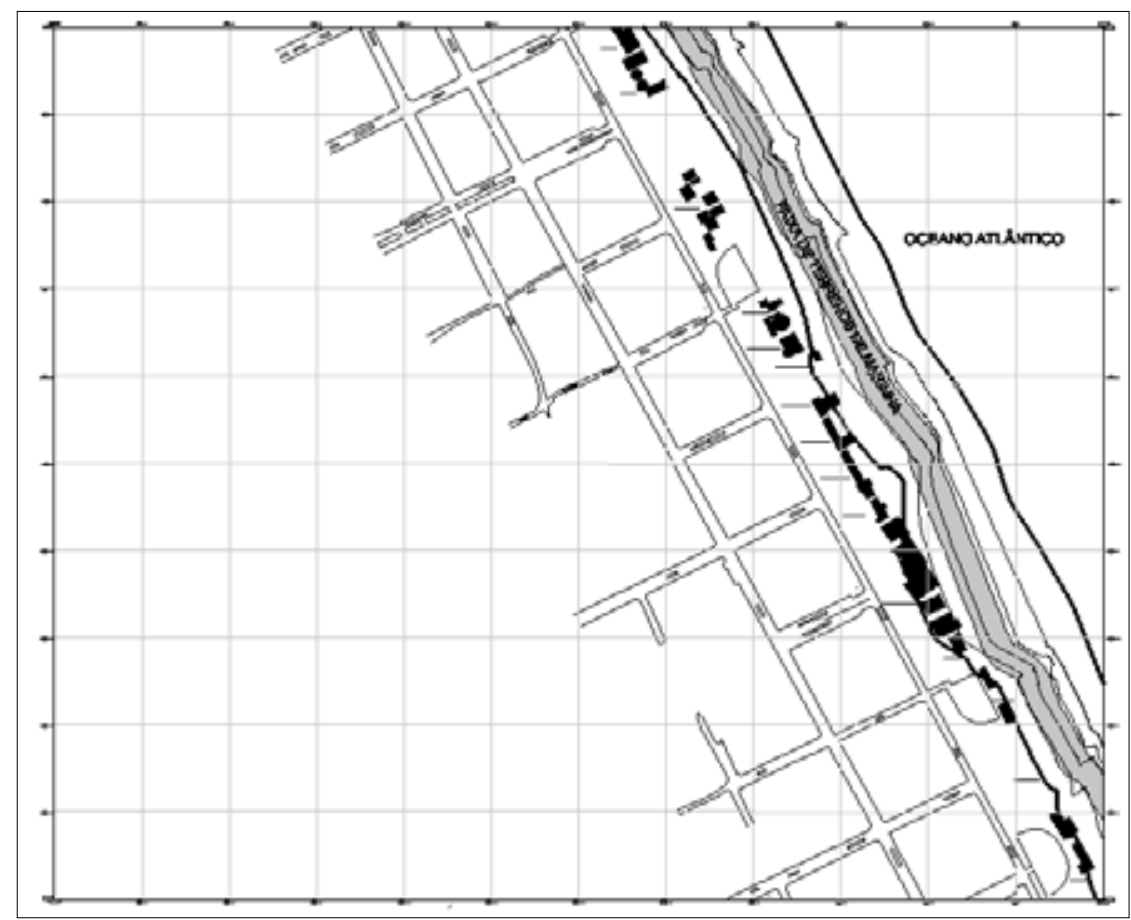

Figura 5 - Faixa de Terreno de Marinha definida pela LPM e LTM

Considerações finais

As análises efetuadas sobre o mapeamento concluíram que, efetivamente, apenas parte de estruturas de algumas barracas ocupa terrenos da União. Para a análise que permitiu identificar a distribuição das edificações e terrenos de Marinha, foram elaboradas 12 folhas, articuladas entre si e na escala de 1:2.000, que recobrem toda a faixa da Praia do Futuro, em Fortaleza-Ceará. A perícia tinha por objetivo identificar que imóvel (barraca) estaria contida na área de terrenos da União.

Foram publicadas teses que comprovam o avanço do NMM global ao longo do tempo, em taxas de até $2 \mathrm{~mm}$ /ano, e apontam que esse avanço decorre, provavelmente, do aquecimento global.

Blitzkow et al. (2001) afirma que "o nível médio do mar de 1831, por todas as estimativas conhecidas, está abaixo do nível médio do mar atual (2001), pois o nível médio do mar de longo termo está aumentando 
na costa brasileira.” Afirma, também, que medidas do marégrafo do Instituto Oceanográfico da USP, com registro contínuo a partir do ano de 1954, considerada a mais longa série temporal conhecida no Brasil, ratificam que o NMM avança $40 \mathrm{~cm} /$ século. Além disso,

a tendência média estimada para todo o planeta, estabelecida por Douglas (1991)(18cm/século), a partir de medidas de longo período (maiores do que 60 anos) do nível do mar, obtidas em marégrafos distribuídos em todos os continentes é aceita pelo IPCC (Intergoverrnmental Panel for Climatic Changes), da WMO (World Meteorological Organization) e UNEP (United Nations Environment Programme), como a melhor estimativa global: 0,0018m/ano. A variação do nível do mar no porto de Brest, França $(9,6 \mathrm{~cm} / \mathrm{século})$, uma das mais longas séries de medida conhecida no mundo, teve início no ano de 1807 e aponta para o 0,00096m/ano, o que corresponde a um aumento de 0,16m no período 1831-2000. (Blitzkow, 2001)

O IBGE (2006) divulgou resultados preliminares demonstrando que, em Imbituba-SC, o NMM subiu $1 \mathrm{~cm}$. Os registros, ainda segundo o IBGE (2006), mostram que de dezembro de 2001 a dezembro de 2006, o mar subiu em média 2,5mm por ano. Para Fortes (2007), "a elevação de Imbituba-SC apresenta como causa o aquecimento global, e é condizente com levantamentos feitos em outros lugares do mundo, que apontam uma elevação média anual entre 1 e 2 mm.”

A determinação da LPM, com retrovisão a 1831, torna-se mais plausível quando se adotam resultados de pesquisas que comprovam o avanço do nível dos mares a taxas bem definidas, com comprovação e respaldo científicos. De forma contrária a esta posição, não há referências geodésicas que permitam orientar a determinação da variação do NMM ao longo do período considerado: 1831 a 2009.

\section{Referências}

BLITZKOW, D. et al. Nível do mar relativo ao ano de 1831 na Praia do Pulso. São Paulo, 2001. p. 11.

FORTES, L. P. IBGE registra aumento no nível do mar no RJ e em SC. Jornal Folha de S. Paulo, São Paulo, 27 jun. 2007, Caderno de Ciências, p. A14.

IBGE - Monitoramento do Nível do Mar através da RMPG, Cursos Técnicos. Rio de Janeiro-RJ, p. 3, 2006. 
IBGE - RBMC. Rede Brasileira de Monitoramento Contínuo dos Sistemas GNSS. Disponível em: <http//www.ibge.gov.br/Geociências/RBMC. Acesso em: 23 jul. 2010.

MONICO, J. F. G. Posicionamento pelo GNSS: descrição, fundamentos, aplicações. São Paulo: Unesp, 2008. 476p.

Paulo Roberto Lopes Thiers - Engenheiro cartógrafo, mestre em Geografia pela Universidade Estadual do Ceará. Doutorando em Geografia pela Universidade Federal do Ceará e professor pela mesma universidade.

Recebido para publicação em dezembro de 2011 Aceito para publicação em março de 2012 